\title{
Cloning, sequencing and mutagenesis of the genes for aromatic amine dehydrogenase from Alcaligenes faecalis and evolution of amine dehydrogenases
}

\author{
Andrei Y. Chistoserdov \\ Tel: +1 631632 9233. Fax: +1 631632 8820. e-mail: andrei@notes.cc.sunysb.edu
}

Marine Sciences Research Center, State University of New York at Stony Brook, Stony Brook, NY 117945000, USA

\begin{abstract}
The nucleotide sequence of the aromatic amine utilization (aau) gene region from Alcaligenes faecalis contained nine genes (orf-1, aauBEDA, orf-2, orf-3, orf-4 and hemE) transcribed in the same direction. The aauB and aauA genes encode the periplasmic aromatic amine dehydrogenase (AADH) large and small subunit polypeptides, respectively, and were homologous to mauB and mauA, the genes for the large and small subunits of methylamine dehydrogenase (MADH). aauE and aauD are homologous to mauE and mauD and apparently carry out the same function of transport and folding of the small subunit polypeptide in the periplasm. No analogues of the mauF, mauG, mauL, mauM and mauN genes responsible for biosynthesis of tryptophan tryptophylquinone (the prosthetic group of amine dehydrogenases) were found in the aau cluster. orf-2 was predicted to encode a small periplasmic monohaem c-type cytochrome. No biological function can be assigned to polypeptides encoded by orf-1, orf-3 and orf-4 and mutations in these genes appeared to be lethal. Mutants generated by insertions into mauD were not able to use phenylethylamine, tyramine and tryptamine as a source of carbon and phenylethylamine, 3'-hydroxytyramine (dopamine) and tyramine as a source of nitrogen, indicating that AADH is the only enzyme involved in utilization of primary amines in A. faecalis. AADH genes are present in Alcaligenes xylosoxydans subsp. xylosoxydans, but not in other $\beta$ - and $\gamma$-proteobacteria. Phylogenetic analysis of amine dehydrogenases (MADH and AADH) indicated that AADH and MADH evolutionarily diverged before separation of proteobacteria into existing subclasses.
\end{abstract}

Keywords: aau genes, methylamine dehydrogenase, proteobacteria, methylotrophy

\section{INTRODUCTION}

Considerable amounts of carbon and nitrogen in the environment are sequestered in the form of amines released there by live organisms or post-mortem (Tarr, 1954). The role of amines in the cycling of these elements is as yet unknown. Being abundant in the environment, amines have an impact on humans. Volatile amines,

Abbreviations: $A A D H$, aromatic amine dehydrogenase; $M A D H$, methylamine dehydrogenase; TTQ, tryptophan tryptophylquinone.

The GenBank accession number for the aau gene cluster from Alcaligenes faecalis is AF302652. especially methylated amines, have been implicated in the production in the atmosphere of nitric oxide, an important greenhouse gas (Van Neste et al., 1987). A constantly growing source of amines in the environment is from human activity. The degradation of amines in nature therefore plays an important role in sustaining their proper balance in organisms and the environment. Oxidation of primary amines is a widespread process in nature, found in both eukaryotic and prokaryotic organisms and carried out by a number of enzymes including quinoproteins (McIntire \& Hartmann, 1992).

Quinoproteins degrading amines are unusual in that their prosthetic groups are synthesized from amino acid moieties of their polypeptide chains. There are two 
groups of quinoproteins able to oxidize amines: amine oxidases (AOs) and amine dehydrogenases. AOs are found in both eukaryotes and prokaryotes (McIntire \& Hartmann, 1992), whereas amine dehydrogenases have been found only in bacteria. Until recently, methylamine dehydrogenase (MADH) was the only known amine dehydrogenase. MADH enzymes from different sources consist of two small and two large subunits with molecular masses ranging from 13 to $15 \mathrm{kDa}$ and from 40 to $45 \mathrm{kDa}$, respectively, and in all known cases this enzyme is periplasmic (Eady \& Large, 1968; Matsumoto, 1978; Haywood et al., 1982; Kenny \& McIntire, 1983; Husain \& Davidson, 1987; Kiriuchin et al., 1990). The small subunit has a quinone prosthetic group called tryptophan tryptophylquinone (TTQ), which is synthesized from two tryptophans of the MADH small subunit polypeptide (McIntire et al., 1991).

A novel type of amine dehydrogenase, called aromatic amine dehydrogenase (AADH), has a much different substrate specificity from that of MADH (Iwaki et al., 1983). AADH has been found so far only in Alcaligenes faecalis during growth of the bacterium on medium containing phenylethylamine (Nozaki, 1987). AADH resembles MADH in many of its properties (Govindaraj et al., 1994). It has two large and two small subunits with molecular masses of 39 and $18 \mathrm{kDa}$, respectively. $\mathrm{AADH}$ is also localized in the periplasm (Zhu et al., 1999). In addition, the chromogenic group of AADH is associated with the small subunit polypeptide and it has been shown to be a quinone. The visual and Raman spectra of both AADH and MADH are nearly identical. These data suggested that the prosthetic group of AADH is TTQ. Azurin has been shown to act as an in vitro electron acceptor for AADH (Edwards et al., 1995).

The genetics of MADH has been extensively studied. Complete or partial sequences are available for mau gene clusters from Methylobacterium extorquens AM1 (Chistoserdov et al., 1990, 1994a), two strains of Paracoccus denitrificans (Van Spanning et al., 1990; Ubbink et al., 1991; Chistoserdov et al., 1992; Huitema et al., 1993; Van der Palen et al., 1995, 1997), Methylophilus methylotrophus W3A1 (Chistoserdov et al., 1994b), Methylobacillus flagellatus KT (Gak et al., 1995, 1997) and 'Methylomona' sp. J (Taguchi et al., 1997). All mau genes are clustered in the order mauFBEDACJGLMN (mauCJ and mauL can be missing in some bacteria). The mauB, mau $A$ and mauC genes encode the large and small subunit polypeptides of $\mathrm{MADH}$ and amicyanin, respectively. The products of mauE and mauD are likely to be involved in transport and folding of the small subunit polypeptide in the periplasm (Lidstrom \& Chistoserdov, 1993; Van Der Palen et al., 1997), whereas mauF and mauGLM are involved in TTQ biosynthesis (Lidstrom \& Chistoserdov, 1993; Chistoserdov et al., 1994a; Van der Palen et al., 1995; Gak et al., 1997). The mauFBEDACJGLMN genes are sufficient to synthesize enzymically active MADH (Van der Palen et al., 1995; Graichen et al., 1999).
Nothing is known about the genetics of AADH. Therefore, the goals of this research were to clone aromatic amine $u$ tilization (aau) genes and elucidate their organization, to verify whether AADH is the only enzyme present in $A$. faecalis able to oxidize primary amines and to study the distribution of AADH genes among other proteobacteria.

\section{METHODS}

Bacterial strains and growth conditions. The bacterial strains and plasmids used in this work are shown in Table 1. All Escherichia coli, Pseudomonas aeruginosa, A. faecalis, Alcaligenes xylosoxydans (A. xylosoxydans subsp. xylosoxydans), Ralstonia eutropha and Bordetella bronchiseptica strains were grown in liquid or on solid Luria-Bertani medium as described by Maniatis et al. (1982). Bordetella pertussis, Neisseria gonorrhoeae and Neisseria mucosa were grown on plates containing media recommended by the ATCC (ATCC Catalogue of Bacteria \& Bacteriophages). Methylophilus methylotrophus W3A1 was grown in liquid OK medium (Owens \& Keddie, 1969) supplemented with $0.3 \%$ (w/v) methylamine. E. coli, Ps. aeruginosa, R. eutropha, A. faecalis and A. xylosoxydans strains were also grown in the OK mineral medium supplemented with $0.25 \%(\mathrm{w} / \mathrm{v})$ of a source of carbon (acetate, succinate, phenylethylamine, tyramine, dopamine, tryptamine, histamine, phenylmethylamine). Nitrogen-free OK medium was prepared by substituting sodium-containing salts for ammonia-containing salts in equimolar concentrations. It was supplemented with acetate $(0 \cdot 2 \%, \mathrm{w} / \mathrm{v})$ as a source of carbon and one of the aromatic amines or methylamine $(0.05 \%, \mathrm{w} / \mathrm{v})$ as a source of nitrogen. During growth and transformation of E. coli strains, appropriate antibiotics were added according to Maniatis et al. (1982), except that the concentration of chloramphenicol for pAYC63 derivatives was $0.01 \mathrm{mg} \mathrm{ml}^{-1}$. A. faecalis is resistant to virtually all known antibiotics and mercury ions, except kanamycin and rifamycin, which were used in concentrations of $4 \mathrm{mg} \mathrm{ml}^{-1}$ and $0 \cdot 2 \mathrm{mg} \mathrm{ml}^{-1}$, respectively.

AADH assay. Biomass of $A$. faecalis and A. xylosoxydans was grown in liquid $\mathrm{OK}$ medium as described above with phenylethylamine as a source of carbon. Crude extracts were obtained and $\mathrm{AADH}$ activity measurements were carried out according to Nozaki (1987). One unit of the AADH activity is defined as the amount of enzyme required to reduce $1 \mathrm{nmol}$ dichlorophenolindophenol $\mathrm{min}^{-1}$. Protein concentrations were measured as described earlier (Whitaker \& Granum, 1980).

DNA-DNA hybridization. DNA-DNA hybridization and random prime DNA labelling was carried out using the DIG High Prime Labelling and Detection Starter Kit I according to the recommendations of the manufacturer (Boehringer Mannheim). The oligonucleotide AC14 (GGNGCNGAYGAYCAYATHAT) was labelled using The Genius System Oligonucleotide Tailing Kit (Boehringer Mannheim). The temperature of hybridization $(6 \times \mathrm{SSC}, 0 \cdot 1 \% \mathrm{SDS} ; 1 \times \mathrm{SSC}$ is $0 \cdot 15 \mathrm{M}$ sodium chloride and $0 \cdot 015 \mathrm{M}$ sodium citrate solution, $\mathrm{pH} 7 \cdot 0)$ and washes $\left(0.5 \times\right.$ SSC, $0.1 \%$ SDS) was $68^{\circ} \mathrm{C}$ for homologous DNA-DNA hybridizations (both probe and target DNA from A. faecalis). For heterologous DNA-DNA hybridizations (probe DNA from A. faecalis and target DNA from another bacterium), the temperatures for hybridization and washes were variable from 41 to $56^{\circ} \mathrm{C}$ with $3{ }^{\circ} \mathrm{C}$ increments. In experiments with the oligonucleotide AC14 as 
Table 1. Bacterial strains and plasmids used in this study

\begin{tabular}{|c|c|c|}
\hline Strain or plasmid & Description & Source or reference* \\
\hline \multicolumn{3}{|l|}{ Strains } \\
\hline \multicolumn{3}{|l|}{ E. coli } \\
\hline $\mathrm{DH} 5 \alpha$ & $\begin{array}{l}\mathrm{F}^{-} \phi 80 \mathrm{~d}(\text { lac } \Delta Z) \mathrm{M} 15 \text { hsdR17 supE44 thi-1 } \\
\text { gyrA96 endA1 recA1 relA? } \\
\Delta(\text { lacZYA-argF }) \text { U169 }\end{array}$ & New England Bio-Labs \\
\hline S17-1 & $\begin{array}{l}\mathrm{F}^{-} \Delta \text { proAB thi-1 recA56 RP4- } 2\left[\mathrm{Tc}^{\mathrm{R}}:: \mathrm{Mu}\right. \\
\left.\mathrm{Km}^{\mathrm{R}}:: \operatorname{Tn} 7\left(\mathrm{~T}^{\mathrm{R}} \mathrm{Sm}^{\mathrm{R}}\right)\right] \text { integrated into the } \\
\text { chromosome }\end{array}$ & Simon (1984) \\
\hline \multicolumn{3}{|c|}{ - } \\
\hline Wild-type & & S. Edwards \\
\hline $\mathrm{Rf}^{\mathrm{R}}$ & rif-1 & \\
\hline Pea1 & aauD:: $\mathrm{Km}^{\mathrm{R}}$ rif-1 & \\
\hline Ps. aeruginosa PAO1 & Wild-type & $\begin{array}{c}\text { B. Holloway, Monash } \\
\text { University, Australia }\end{array}$ \\
\hline B. bronchiseptica & Wild-type & ATCC 10580 \\
\hline B. pertussis & Wild-type & ATCC 9340 \\
\hline R. eutropha & Wild-type & ATCC 17697 \\
\hline A. xylosoxydans & Wild-type & ATCC 15175 \\
\hline N. gonorrhoeae & Wild-type & ATCC 19424 \\
\hline N. mucosa & Wild-type & ATCC 19695 \\
\hline $\begin{array}{l}\text { Methylophilus } \\
\text { methylotrophus W3A1 }\end{array}$ & Wild-type & $\begin{array}{l}\text { F. S. Mathews, } \\
\text { Washington } \\
\text { University, USA }\end{array}$ \\
\hline \multicolumn{3}{|l|}{ Plasmids } \\
\hline pRK310 & $\mathrm{Tc}^{\mathrm{R}} l a c \mathrm{Z}^{\prime} m o b^{+} \mathrm{IncP}$ & Ditta et al. (1985) \\
\hline pUC19 & $\mathrm{Ap}^{\mathrm{R}} l a c \mathrm{Z}^{\prime}$ & New England Bio-Labs \\
\hline pAYC61 & $\mathrm{Ap}^{\mathrm{R}} \mathrm{Tc}^{\mathrm{R}} m o b^{+}$IncColEI & $\begin{array}{l}\text { Chistoserdov et al. } \\
\text { (1994a) }\end{array}$ \\
\hline pAYC63 & $\mathrm{Cm}^{\mathrm{R}} \operatorname{lac} \mathrm{Z}^{\prime}$ & $\begin{array}{l}\text { Chistoserdov et al. } \\
\text { (1992) }\end{array}$ \\
\hline pUC4K & $\mathrm{Ap}^{\mathrm{R}} \mathrm{Km}^{\mathrm{R}}$ & Pharmacia \\
\hline
\end{tabular}

*Where no source or reference is given, the strain or plasmid was derived in this study.

a probe, the temperature of hybridization and washes was $42^{\circ} \mathrm{C}$.

DNA manipulations. Plasmid isolation, E. coli strain transformation, preparative isolation of the DNA fragments from agarose gels, restriction endonuclease digestion, ligation and blunting of ends with Klenow fragment or T4 DNA polymerase were carried out as described by Maniatis et al. (1982). Chromosomal DNA of all bacterial strains was isolated in accordance with the procedure of Marmur (1961). The general strategy of construction and analysis of partial gene libraries was as described by us earlier (Chistoserdov et al., 1990, 1994b). The oligonucleotide AC14 was designed based on the $\mathrm{N}$-terminal sequence of the AADH small subunit polypeptide (GADHII; Govindaraj et al., 1994). A partial clone library was constructed in the vector pRK310, using the fraction of the $B c l \mathrm{I}-B g l \mathrm{II}$ digest of the $A$. faecalis chromosome, which hybridized to AC14 (not shown). This fraction had DNA fragments with an approximate size range of $1 \cdot 6-1 \cdot 9 \mathrm{~kb}$. These fragments were collected in a well in agarose gels as described by Maniatis et al. (1982) and cloned into pRK310. Clones with positive hybridization to the AC14 probe were identified (approx. 1 per 300 white colonies); plasmids isolated from the positive clones were shown to contain an identical insert of $\sim 1.7 \mathrm{~kb}$ in size.

DNA sequencing. DNA sequencing was performed by the dideoxy chain termination method on both strands in the SUNY Sequencing Facility on an Applied Biosystems sequencer, model 370A. Plasmid pAYC63 $\left(\mathrm{Cm}^{\mathrm{R}}\right.$; Chistoserdov et al., 1992) was used as a vector for subcloning and sequencing in addition to pUC19 $\left(\mathrm{Ap}^{\mathrm{R}}\right)$.

Matings. Biparental matings were conducted using the E. coli strain S17-1 as described previously (Simon, 1984).

Construction of insertional mau strains. Insertion mau mutants were constructed by homologous recombination as described previously (Ruvkun \& Ausubel, 1981). The $\mathrm{Km}^{\mathrm{R}}$ cassette from the plasmid pUC4K was used as a selective inactivating marker and the plasmid pAYC61 as a suicide vector (Chistoserdov et al., 1994a).

Computer analysis of DNA and protein sequences. Computer analysis was carried out using the GCG (Wisconsin Package version 9.1 of the Genetics Computer Group) and PCGene (Genofit) program packages. DNA and protein sequences were compared to the GenBank and SWISS-PROT databases 
by the BLAST and FASTA programs (Wisconsin Package version 9.1 of the Genetics Computer Group).

The phylogenetic trees were constructed using two independent algorithms: distance analyses with Jukes-Cantor corrections [programs DNADIST (Jukes-Cantor) and FITCH from the PHYLIP package (version 3.5c, http://evolution. genetics.washington.edu/phylip.html] and parsimony using PAUP (version 3.1.1).

\section{RESULTS AND DISCUSSION}

\section{Cloning and nucleotide sequence of the aau gene cluster from $A$. faecalis}

A $1.7 \mathrm{~kb} \mathrm{Bcl}$ fragment which hybridized with the AC14 probe was cloned as described in Methods. This fragment was completely sequenced and three open reading frames (ORFs) were identified in it. One of these ORFs was truncated and encoded a polypeptide containing the previously determined N-terminal sequence of the AADH small subunit polypeptide (Govindaraj et al., 1994). Two other ORFs encoded polypeptides highly homologous to MauE and MauD and were called aauE and aauD.

To clone other aau genes, additional cloning experiments were carried out. Chromosomal DNA of $A$. faecalis was digested with EcoRI and hybridized with the labelled $1.7 \mathrm{~kb}$ fragment. Two, $2 \mathrm{~kb}$ and $4.6 \mathrm{~kb}$, EcoRI fragments were identified by hybridization. Both fragments were excised from agarose gels, cloned and sequenced as described above.

\section{Computer analysis of the aau gene cluster organization and polypeptides encoded by the mau gene cluster}

ORFs for nine genes (orf-1, aauBEDA, orf-2, orf-3, orf4 and hemE) were found in the two EcoRI fragments, all putatively transcribed in the same direction (Fig. 1).
Based on identity with the corresponding genes of the mau gene cluster, the second and fifth ORFs were tentatively identified as $a a u B$ and $a a u A$ genes. They encode the periplasmic aromatic amine dehydrogenase large (346 aa, $38222 \mathrm{Da}$ ) and small (182 aa, $19652 \mathrm{Da})$ subunit polypeptides, respectively. The identity between AauA and MauA from Methylophilus methylotrophus W3A1 was $60 \%$ and the identity between AauB and $\mathrm{MauB}$ from the same bacterium was $31 \%$. The third and fourth genes in this gene cluster encode polypeptides highly similar to the MauE and MauD polypeptides; these polypeptides were therefore denoted AauE (213 aa, $22527 \mathrm{Da})$ and AauD (213 aa, $22917 \mathrm{Da})$. The identities between MauE (from Methylophilus methylotrophus W3A1) and AauE and MauD (from Methylophilus methylotrophus W3A1) and AauD were 45 and $60 \%$, respectively. AauB, AauA and AauD are putative periplasmic polypeptides similar to their Mau counterparts. A leader sequence of AauD resembles that of MauD in that it lacks positively charged amino acids in its N-terminus, which are commonly found in all other leader sequences. Both AauE and MauE are membrane-spanning polypeptides with four predicted hydrophobic helices. AauA and MauAs are very similar (Fig. 2), particularly around the areas where tryptophans involved in TTQ biosynthesis are located. Overall, all amino acids which are believed to be involved in formation of the active centre and catalysis of TTQcontaining enzymes (Chen et al., 1991) are identical in both AauA and MauA (Asp32, Asp76, Thr122, Trp57 and Trp108, Par. denitrificans numbering). The only exception is Tyr119 in MauA, which is replaced with Phe in AauA. MauA and AauA share similarities in their leader polypeptides (Fig. 1): both leader polypeptides are unusual and possess the 'double-Arg' motif, which is believed to be necessary to transport into the periplasm polypeptide with covalently attached coenzymes or prosthetic groups (Berks, 1996).

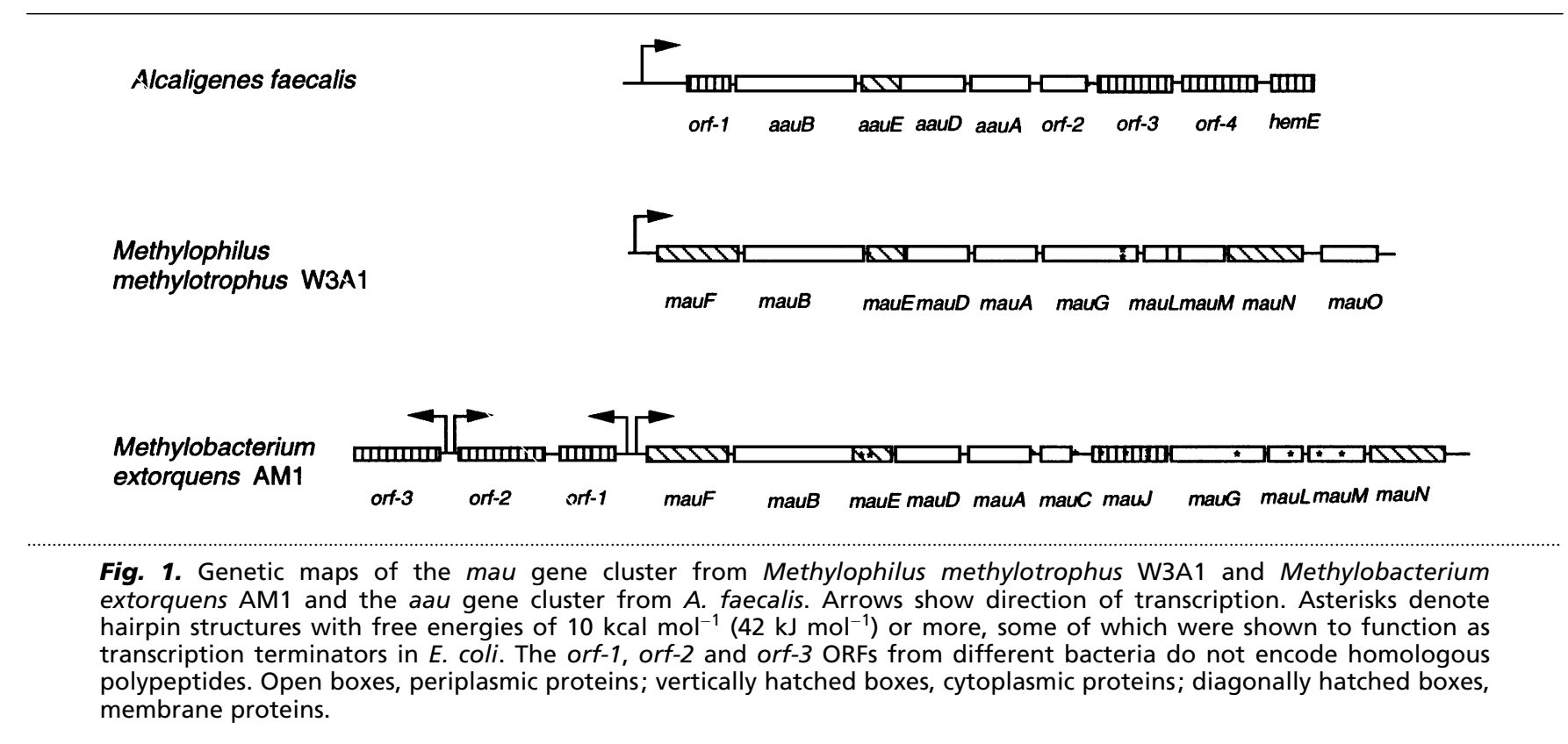


A M--LGNFR---FDDMVEKLSRRVAGQTSRRSVIGKLGTAML-GIGLV-PL B M--LGNFR---FDDMVEKLSRRVAGRTSRRGAIGRLGT-VLAGAALV-PL C MRWLDKF---G-----ESLSRSVAHKT SRRS-VGKL----MVGSAFVLPV D M----K-KNTGFDSGIEKLARKTASKTGRRSFIGKLG-GFLVGSALL-PL E M---K-KDTGFDSKIEKLARTTASKTGRRGF IGRLG-GFLVGSALL-PL F M--LGKSQ---FDDLFEKMSRKVAGHTSRRGFIGRVGTAV-AGVALV-PL G M---TK-K-LGLDAAIEKLSRRTANKTGRRSFVGKLGG-FLVGATLL-PI

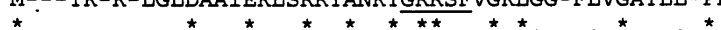

A LPVDRRGRVSR-ANA $\downarrow$ ADAPA-GT-.---DPRAKWVPQDNDIQACDYWRH B LPVDRRGRVSR-ANA $\downarrow_{\text {AG-PAEGV-----DPRAKWQPQDNDIQACDYWRH }}$

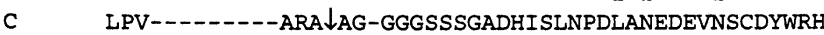
D LPVDRRGRMNE-AHA E LPVDRRSRLGGEVQA $\downarrow_{\text {ATTGN-LT-.----RSGFKPQDKDPKACDYWRH }}$ F LPVDRRGRVSR-ANA $\downarrow_{\text {AESSA--G--.---DPRGKWKPQDNDVQSCDYWRH }}$ G LPVDRRGRLSE-AHA L------ASVSEGDELRSKWTPQDQDPQSCDYWRH

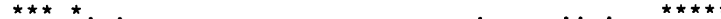

CSIDGNICDCSGGSLTNCPPGTKLATASWVASCYNPTDGQSYLIAYR-DC CSIDGNICDCSGGSLTNCPPGTKLATASWVASCYNPTDGQSYLIAYR-DC CAVDGFLCSCCGGTTTTCPPGSTPSPISWIGTCHNPHDGKDYLIISYHDC CSIDGNLCDCCGGSLTSCPPGTELSPSSWVASCFNPGDGQTYLIAYR-DC CTIDGNLCDCCGGTLTSCPPGSSLSPSSWVASCYNPGDQQTYLIAYR-DC CSIDGNICDCSGGSLTSCPPGTKLASSSWVASCYNPTDKQSYLISYR-DC CSIDGNVCDCCGGTLTSCPPGTSLSPSSWVASCYNPGDGQTYLIAYR-DC

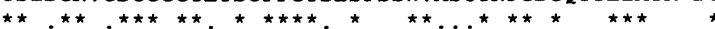

CGYNVSGRCPCLNTEG-ELPVYRPEFA--NDI IWCFGAEDDAMTYHCTIS CGYNVSGRCPCLNTEG-ELPVYRPEFA--NDI IWCFGAEDDAMTYHCTIS CGKTACGRCQC-NTQTRERPGY--EFFLHNDVNWCM-A-NEN-SFHCTTS CGKQTCGRCNCVNVQG-ELPVYRPEFN--NDIVWCFGADNDAMTYHCTVS CGKOTCGRCNCVNTOG-ELPVYRPEFN--NDIVWCFGADNDAMTYHCTIS CGANVSGRCACLNTEG-ELPVYRPEFG--NDI IWCFGAEDDAMTYHCTIS CGKQTCGSCACLNTEG-ELPVYRPEFS--NDIVWCFGAENDDMTYHCTIS

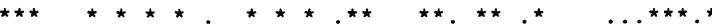

PIVGKAS-

PIVGKAS-

VLVGLAKN

PIVGKAS-

PIVGKAS-

PIVGKAS-

PVVGKAS-

$\star \star \star$

Fig. 2. Alignment of amino acid sequences of MauA or AauA from: A, Par. denitrificans; B, 'Thiobacillus versutus'; C, A. faecalis; D, Methylobacillus flagellatus KT; E, Methylophilus methylotrophus W3A1; F, Methylobacterium extorquens AM1; G, Methylophaga thalassica S1. Tryptophans involved in TTQ assembly are shown in bold. The double Arg motif is underlined. Vertical arrows indicate the signal peptidase cleavage site. Asterisks indicate amino acids that are identical in all sequences; dots indicate conservative substitutions.

The first ORF (orf-1) was truncated. However, 59 amino acids encoded by orf- 1 were sufficient to ascertain that Orf- 1 is not similar to MauF usually found in this position in mau gene clusters. Moreover, a homology search in the GenBank and SWISS-PROT databases did not reveal any polypeptides homologous to Orf- 1 .

The ORF immediately downstream of aauA (orf-2) was predicted to encode a small periplasmic monohaem $c$ type cytochrome (166 aa, $18580 \mathrm{Da})$. This cytochrome $c$ shares relatively high identity $(36 \%)$ with cytochrome $c_{552}$ from Thermus thermophilus (Titani et al., 1985). The haem $c$ binding sites of cytochrome $c_{552}$ and Orf- 2 are near-identical. The premature form of Orf-2 contains a typical leader sequence, suggesting that this is a periplasmic cytochrome. In mau gene clusters, the mauA gene is followed either by the gene for dihaem cytochrome MauG (in most of methylotrophs) or by the gene for amicyanin, an MADH electron acceptor (in Methylobacterium extorquens AM1 and Paracoccus spp.). However, there is no substantial similarity between Orf-2 and MauG. Insertion mutagenesis experiments (see below) indicated that Orf- 2 is apparently not involved in oxidation of aromatic amines in A. faecalis.

orf- 2 and orf-3 encode cytoplasmic polypeptides 318 (35768 Da) and 295 (29792 Da) amino acids long, respectively. No polypeptides homologous to Orf-2 and Orf-3 were found in the GenBank and SWISS-PROT databases.

The ninth ORF was truncated. A homology search in GenBank revealed that it encodes a polypeptide sharing $59 \%$ identity with uroporphyrinogen decarboxylase from E. coli and therefore it was called hemE.

Thus, no analogues of the mauF, man, mauL, man $M$ and $\operatorname{mauN}$ genes were found in and around the aauBEDA cluster. This is surprising, since polypeptides encoded by these man genes are responsible for the biosynthesis of TTQ, the prosthetic group of amine dehydrogenases. Apparently, aauF, aau $G$, aauL, aauM and aauN genes are located elsewhere in the chromosome of A. faecalis, or TTQ in A.faecalis is synthesized by different, unrelated gene products. From the point of view of the selfish operon model (Lawrence \& Roth, 1996), this suggests a more ancient origin of aau genes compared to modern mau genes (see below).

\section{Construction of aau mutants and their properties}

Our preliminary experiments showed that A. faecalis is able to utilize phenylethylamine, tyramine and tryptamine as both carbon and nitrogen sources. In addition, dopamine may serve as a source of nitrogen (it was possible to select mutants with the frequency $10^{-7}$ able to utilize dopamine as a source of carbon). Two other amines, histamine and phenylmethylamine, did not serve as sources of either carbon or nitrogen for $A$. faecalis.

It is known for methylotrophic bacteria that two different amine-oxidizing systems may reside in the same bacterial cell (Chistoserdov et al., 1994a). To determine a number of amine-oxidizing enzymes, a series of aauD mutants was generated. The $\mathrm{Km}^{\mathrm{R}}$ cassette from pUC4K was inserted into aauD in such an orientation that $a p h$ and $a a u A$ were transcribed in the same direction and this construction was introduced into the chromosome of A. faecalis in the suicide vector pAYC61. $\mathrm{Km}^{\mathrm{R}}$ revertants appeared on the plates with a high frequency as large colonies $\left(2 \times 10^{-6}\right)$; however, an equal number of small $\mathrm{Km}^{\mathrm{R}}$ colonies appeared as well. Six large and six small colonies were selected, their DNA was isolated and digested with $B g l \mathrm{II}$ and $B c l \mathrm{I}$ and the digest was hybridized with the labelled $1.7 \mathrm{~kb}$ fragment and the labelled $\mathrm{Km}^{\mathrm{R}}$ cassette. All large colonies did not contain inserts, whereas all six small colonies contained the $\mathrm{Km}^{\mathrm{R}}$ cassette. Of the six clones with the $\mathrm{Km}^{\mathrm{R}}$ cassette, four contained only the cassette itself, whereas two other clones contained the entire suicide vector. 
The growth spectra of the four aauD:: $\mathrm{Km}^{\mathrm{R}}$ mutants and the wild-type strain of $A$. faecalis were studied. All four mutants turned out to be identical and differ from the wild-type in that they could not utilize phenylethylamine, tyramine and tryptamine as sources of carbon. They also lost the ability to utilize phenylethylamine, tyramine and dopamine as sources of nitrogen. Tryptamine still served as a source of nitrogen. It is possible that $A$. faecalis is able to oxidize the indole moiety of tryptamine and, therefore, to use it as a source of nitrogen. Thus, it appears that AADH is the only enzyme involved in utilization of primary amines in $A$. faecalis.

Based on a homology search in GenBank, no biological function can be assigned to polypeptides encoded by orf1 , orf-3 and orf-4. Although orf- 2 encodes a $c$-type cytochrome, its biological function is unclear. The cloned portion of orf- 1 is very short and therefore this gene cannot be used for insertional mutagenesis. Therefore, the $\mathrm{Km}^{\mathrm{R}}$ cassette was inserted into each of the orf2, orf-3 and orf- 4 genes and cloned into the suicide vector pAYC61. The resulting suicide plasmids were introduced into $A$. faecalis in a manner similar to that with aauD. Only large colonies were generated in each of the three matings; 400 colonies randomly picked from each mating were re-streaked on plates with mineral medium supplemented with tyramine or acetate. None of the colonies had any detectable phenotype. Finally, 100 randomly picked colonies for each mating were hybridized with the $\mathrm{Km}^{\mathrm{R}}$ cassette. None of 300 checked colonies contained an insertion of the $\mathrm{Km}^{\mathrm{R}}$ cassette. Thus, it appears that insertional mutations in orf-2, orf3 and $o r f-4$ are lethal. Apparently, the products encoded by these genes are essential for $A$. faecalis under the tested growth conditions.

\section{Distribution of aau genes among other proteobacteria}

A. faecalis is the only bacterium known so far to produce AADH. On the other hand, MADH is found in at least three different subclasses of proteobacteria. To ascertain the distribution of the AADH enzymic system among other proteobacteria, we carried out a series of DNA-DNA hybridization experiments.

We selected a number of $\beta$-proteobacteria closely related to A. faecalis: A. xylosoxydans, two Bordetella species and two Neisseria species. R. eutropha is also a $\beta$ proteobacterium but it is more evolutionarily distant from A. faecalis (Busse \& Auling, 1992). Two $\gamma$ proteobacteria used in this study were E. coli and Ps. aeruginosa. E. coli served as a negative control since it is known that its genome does not contain genes for AADH. Methylophilus methylotrophus W3A1 was used as a positive control.

The growth spectra of A. xylosoxydans, R. eutropha and Ps. aeruginosa on aromatic amines (both Bordetella and Neisseria spp. are fastidious and would not grow in mineral medium) were studied. A. xylosoxydans showed a growth pattern identical to that of A. faecalis. Neither A. faecalis nor A. xylosoxydans showed methylotrophic or methazotrophic growth. Ps. aeruginosa used only histamine as a source of carbon and dopamine and histamine as sources of nitrogen. R. eutropha did not use any amine as either carbon or nitrogen sources.

AADH activity with phenylethylamine as a substrate was measured in crude extracts from both $A$. faecalis and A. xylosoxydans and was comparable: 95 and 87 units (mg protein $)^{-1}$, respectively. The same extract did not show any detectable activity with methylamine as a substrate.

To verify whether AADH genes are present in the genomes of the selected bacteria, DNA-DNA hybridization experiments were carried out. The $1.7 \mathrm{~kb}$ fragment (see above) was labelled and hybridized with total chromosomal DNA or chromosomal DNA digested with various restriction enzymes (EcoRI, $B a m \mathrm{HI}$, PstI). As expected, chromosomal DNA from A. xylosoxydans gave a positive hybridization signal at $56^{\circ} \mathrm{C}$. Positive hybridization was observed between the $1.7 \mathrm{~kb}$ fragment and chromosomal DNA from Methylophilus methylotrophus W3A1 at $41^{\circ} \mathrm{C}$. However, at this temperature, no hybridization was observed between the $1.7 \mathrm{~kb}$ fragment and bacterial DNA from the other bacteria studied. Thus, DNA-DNA hybridization experiments suggested that $\mathrm{AADH}$ genes are present only in A. xylosoxydans, and not in other $\beta$-proteobacteria (R. eutropha, B. pertussis, B. bronchiseptica, N. gonorrhoeae, N. mucosa), E. coli or Ps. aeruginosa. The presence of AADH activity in crude extracts of $A$. xylosoxydans further confirms this notion.

\section{Phylogeny of amine dehydrogenases}

In addition to AADH genes, sequences for MADH genes from at least six micro-organisms are known. To ascertain the evolution of amine dehydrogenases, amino acid sequences of MADH small subunit polypeptides from Par. denitrificans, 'Thiobacillus versutus' [presently reassigned to Paracoccus versutus (Katayama et al., 1995)], Methylobacterium extorquens AM1, Methylophilus methylotrophus W3A1, Methylophaga thalassica S1, Methylobacillus flagellatus KT and Methylomonas sp. J and the AADH small subunit polypeptide from $A$. faecalis were aligned. The alignment was used to construct phylogenetic trees using distance and parsimony methods. The resulting trees were identical, therefore only the parsimony tree is shown here (Fig. 3). It is not surprising that all MADHs are more related to each other than to AADH. However, if we look at the same tree based on 16S rRNA phylogeny, the picture will be different. Methylophilus methylotrophus W3A1, Methylobacillus flagellatus KT and $A$. faecalis belong to the same $\beta$-subclass of the Proteobacteria. Methylophaga thalassica S1 belongs to the $\gamma$-subclass and is more closely related to these three than to Par. denitrificans or Methylobacterium extorquens AM1 ( $\alpha$-subclass). The overall mauA branching pattern for these methylotrophs is similar to 


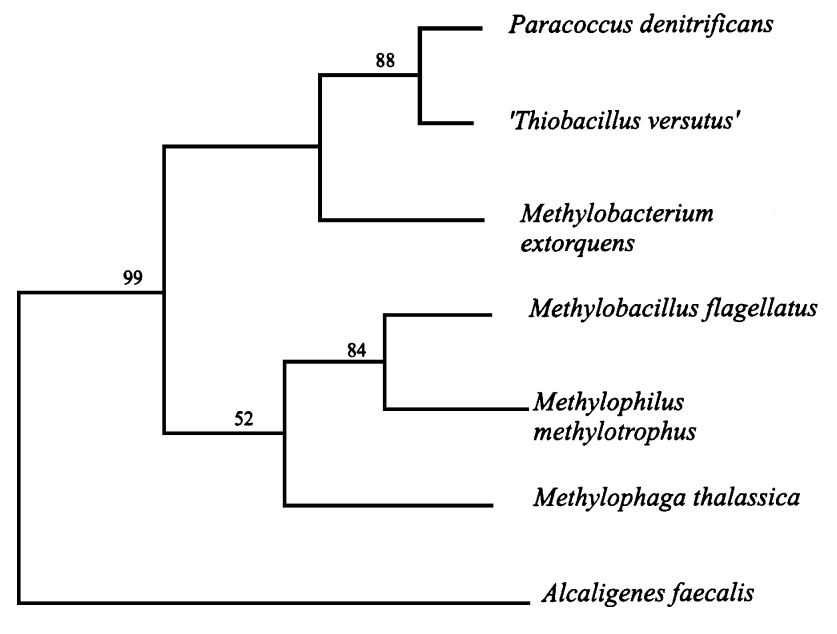

Fig. 3. Phylogenetic relationships of amino acid sequences from amine dehydrogenase small subunit polypeptides. The sequences were aligned by CLUSTAL $w$; phylogenetic trees were constructed by the maximum-parsimony algorithm. Numbers indicate bootstrap confidence values as the percentage of 100 bootstrap replications. Bootstrap percentages less than $50 \%$ are not shown.

the $16 \mathrm{~S}$ rRNA branching pattern. Thus, phylogenetic analysis of amine dehydrogenases (MADH and AADH) indicated that $\mathrm{AADH}$ and $\mathrm{MADH}$ evolutionarily diverged before the separation of proteobacteria into the existing subclasses. This notion is also corroborated by the selfish operon hypothesis (see above).

Further analysis is required to confirm whether the presented view on the evolution of amine dehydrogenases is correct. AADH gene clusters should be cloned and analysed from a larger number of bacteria. Further work is also required to identify missing aau genes which are responsible for TTQ biosynthesis.

\section{Conclusions}

Four genes involved in aromatic amine utilization by $A$. faecalis were cloned (aauBEDA). They share a high similarity with mauBEDA genes and appear to be functionally identical. However, no analogues of the mauF, mauG, mauL, mauM and mauN genes responsible for biosynthesis of TTQ (the prosthetic group of amine dehydrogenases) were found in the aau cluster. According to DNA-DNA hybridization experiments, AADH genes are found so far only in the genus Alcaligenes and not in other $\beta$ - and $\gamma$-proteobacteria. Phylogenetic analysis of amine dehydrogenases (MADH and $\mathrm{AADH}$ ) indicated that AADH and MADH evolutionarily diverged before separation of proteobacteria into the existing subclasses.

\section{ACKNOWLEDGEMENTS}

This work was supported by NIH grant GM52316.

\section{REFERENCES}

Berks, B. C. (1996). A common export pathway for proteins binding complex redox cofactor? Mol Microbiol 22, 393-404.

Busse, H.-J. \& Auling, G. (1992). The genera Alcaligenes and 'Achromobacter'. In The Prokaryotes, pp. 2544-2555. Edited by A. Balows, H. G. Trüper, M. Dworkin, W. Harder \& K.-H. Schleifer. New York: Springer.

Chen, L., Mathews, F. S., Davidson, V. L., Huizinga, E. G., Vellieux, F. M. D., Duine, J. A. \& Hol, W. G. J. (1991). Crystallographic investigations of the tryptophan-derived cofactor in the quinoprotein methylamine dehydrogenase. FEBS Lett 287, 163-166.

Chistoserdov, A. Y., Tsygankov, Y. D. \& Lidstrom, M. E. (1990). Cloning and sequencing of the structural gene for the small subunit of methylamine dehydrogenase from Methylobacterium extorquens AM1: evidence for two tryptophan residues involved in the active center. Biochem Biophys Res Commun 172, 211-216.

Chistoserdov, A. Y., Boyd, J., Mathews, F. S. \& Lidstrom, M. E. (1992). The genetic organization of the mau gene cluster of the facultative autotroph Paracoccus denitrificans. Biochem Biophys Res Commun 184, 1226-1234.

Chistoserdov, A. Y., Chistoserdova, L. V., McIntire, W. \& Lidstrom, M. E. (1994a). The organization of the mau gene cluster from Methylobacterium extorquens: complete nucleotide sequence and mutant characterization. J Bacteriol 176, 4052-4065.

Chistoserdov, A. Y., Mclntire, W., Mathews, F. S. \& Lidstrom, M. E. (1994b). The organization of the mau gene cluster from Methylophilus methylotrophus W3A1. J Bacteriol 176, 4073-4080.

Ditta, G., Schmidhauser, T., Yakobson, E., Lu, P., Liang, X. W., Finlay, D. R., Guiney, D. \& Helinski, D. R. (1985). Plasmids related to the broad host range vector, pRK290, useful for gene cloning and for monitoring gene expression. Plasmid 13, 149-153.

Eady, R. R. \& Large, P. J. (1968). Purification and properties of an amine dehydrogenase from Pseudomonas AM1 and its role in growth on methylamine. Biochem J 106, 245-255.

Edwards, S. L., Davidson, V. L., Hyun, Y.-L. \& Wingfield, P. T. (1995). Spectroscopic evidence for a common electron transfer pathway for two tryptophan tryptophylquinone enzymes. $J$ Biol Chem 270, 4293-4298.

Gak, E. R., Chistoserdov, A. Y. \& Lidstrom, M. E. (1995). Cloning, sequencing and mutation of a gene for azurin in Methylobacillus flagellatum KT. J Bacteriol 177, 4575-4578.

Gak, E. R., Tsygankov, Y. D. \& Chistoserdov, A. Y. (1997). Organization of methylamine utilization genes (mau) from 'Methylobacillus flagellatum' KT: cloning and analysis of mutants. Microbiology 143, 1827-1835.

Govindaraj, S., Eisenstein, E., Jones, L. H., Sanders-Loehr, J., Chistoserdov, A. Y., Davidson, V. L. \& Edwards, S. L. (1994). Aromatic amine dehydrogenase, a second tryptophan tryptophylquinone enzyme. J Bacteriol 176, 2922-2929.

Graichen, M. E., Jones, L. H., Sharma, B. V., van Spanning, R. J. M., Holster, J. P. \& Davidson, V. L. (1999). Heterologous expression of correctly assembled methylamine dehydrogenase in Rhodobacter sphaeroides. J Bacteriol 181, 4216-4222.

Haywood, G. W., Janschke, N. S., Large, P. J. \& Wallis, J. M. (1982). Properties and subunit structure of methylamine dehydrogenase from Thiobacillus A2 and Methylophilus methylotrophus. FEMS Microbiol Lett 15, 79-82.

Huitema, F., Van Beeumen, J., Van Driessche, G., Duine, J. A. \& Canters, G. W. (1993). Cloning and sequencing of the gene coding 
for the large subunit of methylamine dehydrogenase from Thiobacillus versutus. J Bacteriol 175, 6254-6259.

Husain, M. \& Davidson, V. L. (1987). Purification and properties of methylamine dehydrogenase from Paracoccus denitrificans. J Bacteriol 169, 1712-1717.

Iwaki, M., Yagi, T., Horiike, K., Saeki, Y., Ushijima, T. \& Nozaki, M. (1983). Crystallization and properties of aromatic amine dehydrogenase from Pseudomonas sp. Arch Biochem Biophys 220, 253-262.

Katayama, Y., Hiraishi, A. \& Kuraishi, H. (1995). Paracoccus thiocyanatus sp. nov., a new species of thiocyanate-utilizing facultative chemolithotroph, and transfer of Thiobacillus versutus to the genus Paracoccus as Paracoccus versutus comb. nov. with emendation of the genus. Microbiology 141, 1469-1477.

Kenny, W. C. \& McIntire, W. (1983). Characterization of methylamine dehydrogenase from bacterium W3A1: interaction with reductant and amino-containing compounds. Biochemistry 22, 3858-3868.

Kirukhin, M. Y., Chistoserdov, A. Y. \& Tsygankov, Y. D. (1990). Methylamine dehydrogenase from Methylobacillus flagellatum. Methods Enzymol 188, 247.

Lawrence, J. G. \& Roth, J. R. (1996). Selfish operons: horizontal transfer may drive the evolution of gene clusters. Genetics $\mathbf{1 4 3}$, 1843-1860.

Lidstrom, M. E. \& Chistoserdov, A. Y. (1993). Molecular biology and genetics of methylamine dehydrogenases. In Microbial Growth on C1 Compounds, pp. 381-400. Edited by J. C. Murrell $\&$ D. P. Kelly. Andover: Intercept.

McIntire, W. S. \& Hartmann, C. (1992). Copper-containing amine oxidases. In Principles and Applications of Quinoproteins, pp. 97-172. Edited by V. Davidson. New York: Marcel Dekker.

McIntire, W. S., Wemmer, D. E., Chistoserdov, A. Y. \& Lidstrom, M. E. (1991). A new cofactor in a prokaryotic enzyme: tryptophan tryptophylquinone as the redox prosthetic group in methylamine dehydrogenase. Science 25, 817-824.

Maniatis, T., Fritsch, E. F. \& Sambrook, J. (1982). Molecular Cloning: a Laboratory Manual. Cold Spring Harbor, NY : Cold Spring Harbor Laboratory.

Marmur, J. (1961). A procedure for the isolation of deoxyribonucleic acid from microorganisms. J Mol Biol 3, 208-218.

Matsumoto, T. (1978). Methylamine dehydrogenase of Pseudomonas sp. J: purification and properties of the subunits. Biochim Biophys Acta 522, 291-302.

Nozaki, M. (1987). Aromatic amine dehydrogenase from Alcaligenes faecalis. Methods Enzymol 142, 650-655.

Owens, J. D. \& Keddie, R. M. (1969). The nitrogen nutrition of soil and herbage coryneform bacteria. J Appl Bacteriol 32, 338-347.
Ruvkun, G. B. \& Ausubel, F. M. (1981). A general method for sitedirected mutagenesis in prokaryotes. Nature 289, 85-88.

Simon, R. (1984). High-frequency mobilization of Gram-negative bacterial replicons by the in vitro constructed Tn5-mob transposon. Mol Gen Genet 196, 413-420.

Taguchi, K., Kudo, T. \& Tobari, J. (1997). Genetic organization and characterization of the man gene cluster, which concerned the intial step of electron transfer chains involved in methylamine oxidation of the obligate methylotroph Methylomonas sp. strain J. J Ferment Bioeng 84, 502-510.

Tarr, H. L. A. (1954). Microbial deterioration of fish post mortem, its detection and control. Bacteriol Rev 15, 1-15.

Titani, K., Ericsson, L. H., Hon-Nami, K. \& Miyazawa, T. (1985). Amino acid sequence of cytochrome $c_{552}$ from Thermus thermophilus. Biochem Biophys Res Commun 128, 781-787.

Ubbink, M., van Kleef, M. A. G., Kleinjan, D.-J., Hoitink, C. W. G., Huitema, F., Beintema, J. J., Duine, J. A. \& Canters, G. W. (1991). Cloning, sequencing and expression studies of the genes encoding amicyanin and the $\beta$-subunit of methylamine dehydrogenase from Thiobacillus versutus. Eur J Biochem 202, 1003-1012.

Van der Palen, C. J. N. M., Slotboom, D. J., Jongejan, L., Reijnders, W. N. M., Harms, N., Duine, J. A. \& Van Spanning, R. J. M. (1995). Mutational analysis of mau genes involved in methylamine metabolism in Paracoccus denitrificans. Eur J Biochem 230, 860-871.

Van der Palen, C. J. N. M., Reijnders, W. N. M., de Vries, S., Duine, J. A. \& van Spanning, R. J. M. (1997). MauE and MauD proteins are essential in methylamine metabolism of Paracoccus denitrificans. Antonie Leeuwenhoek 72, 219-228.

Van Neste, A., Duce, R. A. \& Lee, C. (1987). Methylamines in the marine atmosphere. Geophys Res Lett 14, 711-714.

Van Spanning, R. J. M., Wansell, C. W., Reijnders, W. N. M., Oltman, L. F. \& Stouthamer, A. H. (1990). Mutagenesis of the gene encoding amicyanin of Paracoccus denitrificans and the resultant effect on methylamine oxidation. FEBS Lett 275, 217-220.

Whitaker, J. R. \& Granum, P. E. (1980). An absolute method for protein determination based on difference in absorbance at 235 and $280 \mathrm{~nm}$. Anal Biochem 109, 156-159.

Zhu, A., Sun, D. \& Davidson, V. L. (1999). Localization of periplasmic redox proteins of Alcaligenes faecalis by a modified general method for fractionating Gram-negative bacteria. J Bacteriol 181, 6540-6542.

Received 1 November 2000; revised 13 March 2001; accepted 23 April 2001. 